\title{
Komposisi Hasil Tangkapan Rawai Siang dan Malam Hari di Kota Panipahan Kecamatan Pasir Limau Kapas Kabupaten Rokan Hilir
}

\author{
Composition of The Catching of Rawai Day and Night in Panipahan City, Pasir \\ Limau Kapas District, Rokan Hilir Regency
}

\author{
Ismail $^{*}$, Syaifuddin ${ }^{1}$, Bustari $^{1}$ \\ ${ }^{1}$ Fakultas Perikanan dan Kelautan, Universitas Riau \\ email:ismailnst52@gmail.com
}

(Received: 29 September 2021; Accepted: 15 November 2021)

\begin{abstract}
ABSTRAK
Kecamatan Pasir limau kapas merupakan satu satunya Kecamatan di Kabupaten Rokan Hilir yang memiliki potensi kelautan dan perikanan dengan jumlah nelayan 4.560 orang nelayan penuh, 222 orang nelayan sambilan dan 16 orang nelayan musiman. Dilihat dari potensi sumberdaya kelautan dan perikanan di Perairan Pasir Limau Kapas Kabupaten Rokan Hilir Provinsi Riau, maka terdapat peluang untuk peningkatan pemanfatan sumberdaya berupa usaha perikanan tangkap oleh masyarakat setempat.Tujuan yang dilakukan pada penelitian ini adalah untuk mengetahui jumlah komposisi hasil tangkapan rawai pada waktu siang dan malam hari yang dilakukan di Kota Penipahan Kecamatan Pasri Limau Kapas Kabupaten Rokan Hilir pada September 2019. Selama penelitian,ikan yang didapat pada hasil tangkapan siang dan malam ada 4 jenis ikan yaitu ikan pari (Dasyatidae), ikan senangin (Eleutheronema tetradactylum), ikan malong (Muraenesox cinereus) dan ikan mata besar (Thunnus obesus). Dimana hasil tangkapan dengan menggunakan menggunakan alat tangkap Rawai adalah sebanyak 668 ekor yang memiliki berat $668 \mathrm{~kg}$, dengan jumlah hasil tangkapan siang hari sebanyak 261 ekor dengan berat $333 \mathrm{~kg}$, sedangkan jumlah hasil tangkapan malam hari sebanyak 407 ekor dengan berat $517 \mathrm{~kg}$. Dapat dilihat bahwa jumlah hasil tangkapan terbanyak tertangkap pada pengoperasian alat tangkap pada malam hari.
\end{abstract}

Kata Kunci: Komposisi hasil tangkapan, Rawai, Siang dan Malam Hari

\begin{abstract}
Pasir Limau Kapas District is the only sub-district in Rokan Hilir Regency that has marine and fisheries potential with 4,560 full fishermen, 222 casual fishermen and 16 seasonal fishermen. Judging from the potential of marine and fishery resources in the waters of Pasir Limau Kapas, Rokan Hilir Regency, Riau Province, there is an opportunity to increase resource utilization in the form of capture fisheries by the local community. and at night in Penipahan City, Pasri Limau Kapas District, Rokan Hilir Regency in September 2019. During the study, the fish caught in the day and night catches were 4 types of fish, namely stingrays (Dasyatidae), happy fish (Eleutheronema tetradactylum), malong (Muraenesox cinereus) and bigeye fish (Thunnus obesus). Where the catch using the Rawai fishing gear is 668 fish which weigh $668 \mathrm{~kg}$, with a total daytime catch of 261 fish weighing $333 \mathrm{~kg}$, while the number of night catches is 407 tails weighing $517 \mathrm{~kg}$. It can be seen that the highest number of catch caught was caught in the operation of fishing gear at night.
\end{abstract}

Keyword: Composition of catch, Longline, Day and Night

\section{Pendahuluan}

Potensi sumberdaya kelautan dan perikanan di Perairan Pasir Limau Kapas Kabupaten Rokan Hilir Provinsi Riau, maka terdapat peluang untuk peningkatan pemanfatan sumberdaya berupa usaha perikanan tangkap oleh masyarakat setempat (Sembiring et al., 2020).

Alat tangakap rawai merupakan alat tangkap yang banyak dioperasikan oleh 
nelayan Jepara untuk menangkap ikan. Hal ini disebabkan karena biaya operasionalnya yang relatif tidak terlalu besar, daerah pengoperasiannya yang tidak terlalu jauh dan bisa dioperasikan sepanjang tahun (Wijayanti et al., 2015). Namun permasalahan yang sering dihadapai nelayan setempat yaitu sulitnya menentukan daerah penangkapan dan tidak adanya daerah yang tetap sehingga menyebabkan waktu penangkapan nelayan mencapai 10 hari dalam satu trip penangkapan yang dioperasikan dengan menggunakan kapal.

Komposisi yang dilihat meliputi jumlah hasil tangkapan pada siang dan malam hari, jumlah individu (ekor) yang tertangkap pada siang dan malam hari, dan jenis-jenis ikan apa saja yang tertangkap pada siang maupun malam hari. Agar diketahui perbandingan komposisi pada kedua waktu tersebut. Banyaknya hasil tangkapan serta keragaman ikan sehingga perlu dilakukan pendataan terhadap komposisi hasil tangkapan alat tangkap rawai pada waktu siang dan malam hari.

\section{Metode Penelitian}

\subsection{Metode Penelitian}

Metode yang digunakan dalam penelitian ini adalah metode survei, yaitu diperoleh dengan cara mengikuti secara langsung operasi penangkapan dengan menggunakan rawai, dan pengambilan data pengukuran kualitas air di daerah penangkapan serta data hasil tangkap dan mewawancarai beberapa nelayan merupakan data primer.

\subsection{Analisis Data}

Analisis tingkat ramah lingkungan dilakukan untuk menyeleksi sifat destruktif atau merusak dari unit penangkapan ikan terhadap sumberdaya ikan, ekosistem, lingkungan sekitar dan masyarakat (Monitja, 2001). Setelah skor atau nilai sudah di dapat, kemudian di buat refrensi poin yang dapat menjadi titik acuan dalam menentukan rangking. Disini skor atau nilai maksimumnya adalah 40 point, sedangkan kategori alat tangkap ramah lingkungan akan di bagi menjadi 4 kategori dengan rentang nilai sebagai berikut:

- 1 - 10 sangat tidak ramah lingkungan

- 11 - 20 tidak ramah lingkungan,
- 21-30 ramah lingkungan,

- 31 - 40 sangat ramah lingkungan.

Semakin tinggi dukungan atau kesesuaian unit penangkapan ikan dengan kriteria keberlanjutan, maka semakin tinggi skor yang diperoleh, dan bila kesesuaian dengan kriteria keberlanjutan tinggi, maka semakin rendah skor yang diberikan (Monitja, 2001).

Kategori kegaiatan penangkapan yang berkelanjutan juga akan di bagi menjadi 4 kategori dengan rentang nilai sebagai berikut:

- 1 - 5 tidak berkelanjutan,

- 6-10 kurang berkelanjutan,

- $11-15$ berkelanjutan,

- 16-20 sangat berkelanjutan

Untuk memproyeksikan kategori kegiatan perikanan diberikan skor maksimum yang diberikan pada setiap komponen. Dengan demikian, maka skor total untuk tingkat ramah lingkungan berkisar 1-40, sedangkan skor total untuk berkelanjutan berkisar 1-20.

Dalam menentukan hasil akhirnya maka jumlah seluruh bobot dari semua kriteria (10 kriteria ramah lingkungan dan 5 kriteria kegiatan penangkapan yang berkelanjutan) yang telah disesuaikan dengan hasil wawancara kemudian dibagi oleh jumlah responden yang telah di wawancara. Data yang diperoleh akan dianalisis secara deskriptif yang bertujuan untuk menggambarkan keadaan data tersebut menggunakan tabel dan menjelaskan tingkat ramah lingkungan alat tangkap serta kegiatan penangkapan ikan yang berkelanjutan.

\section{Hasil dan Pembahasan}

Hasil penelitian menunjukan hasil tangkapan berdasarkan jumlah berat $(\mathrm{kg})$ yang dilakukan selama 12 hari (12 trip) hasil tangkapan yang terbanyak didapat adalah pada malam hari berjumlah $517 \mathrm{~kg}$ dan penangkapan pada siang hari berjumlah 333 $\mathrm{kg}$, dapat dilihat jumlah hasil tangkapan berdasarkan berat $(\mathrm{kg})$ selama penelitia 12 hari (12 trip) adalah $850 \mathrm{~kg}$. Secara keseluruhan jumlah hasil tangkapan pada malam hari lebih banyak dibangdingkan dengan hasil tangkapan yang didapat siang hari yaitu sebanyak $517 \mathrm{~kg}$ dengan rata-rata hasil tangkapan malam hari adalah $294,5 \mathrm{~kg}$. Sedangkan jumlah hasil tangkapan pada siang hari adalah sebanyak $333 \mathrm{~kg}$ dengan rata-rata 
hasil tangkapan siang hari perkapal adalah $166,5 \mathrm{~kg}$.

Hasil tangkapan terbanyak pada saat siang hari yaitu pada kapal Km.S27 sebanyak $174 \mathrm{~kg}$ dan hasil tangkapan terendah pada saat siang hari pada kapal Km. Tiga putra 06 sebanyak $159 \mathrm{~kg}$. Sedangkan hasil tangkapan yang tertinggi pada saat malam hari yaitu pada $\mathrm{Km} . \mathrm{S} 27$ sebanyak $320 \mathrm{~kg}$ dan hasil tangkapan terendah pada saat sesudah tengah malam yaitu pada Km. Tiga putra 06 sebanyak 197 $\mathrm{kg}$ (Tabel 1).

Tabel 1. Perbandingan jumlah berat ikan (kg) pada siang dan malam hari

\begin{tabular}{llllll}
\hline No & Hari/ Bulan & KM. S27 & Km. Tiga Putra 06 & Jumlah & Rata Rata \\
\hline 1 & Siang hari & $174 \mathrm{~kg}$ & $159 \mathrm{~kg}$ & $333 \mathrm{~kg}$ & $166,5 \mathrm{~kg}$ \\
2 & Malam hari & $320 \mathrm{~kg}$ & $197 \mathrm{~kg}$ & $517 \mathrm{~kg}$ & $294,5 \mathrm{~kg}$ \\
\hline & Jumlah & $494 \mathrm{~kg}$ & $356 \mathrm{~kg}$ & $850 \mathrm{~kg}$ & $461 \mathrm{~kg}$ \\
\hline
\end{tabular}

Hasil penelitian menunjukan bahwa jumlah jenis ikan yang tertangkap pada siang hari dan malam hari selama pengamatan ikan pari (Dasyatidae), ikan senangin
(Eleutheronema tetradactylum), ikan malong (Muraenesox cinereus) dan ikan krot krot (pomadasys hasta), seperti pada Tabel 2.

Tabel 2. Perbandingan jumlah jenis ikan pada siang hari dan malam hari

\begin{tabular}{llllllll} 
& & \multicolumn{3}{c}{ Individu (ekor) } & \multicolumn{3}{c}{ Berat $(\mathrm{kg})$} \\
\cline { 3 - 7 } No & Jenis Ikan & Siang hari & Malam hari & Jumlah & Siang hari & Malam hari & Jumlah \\
\hline 1 & Pari & 87 & 69 & 156 & $145 \mathrm{~kg}$ & $108 \mathrm{~kg}$ & $253 \mathrm{~kg}$ \\
2 & Senangin & 91 & 206 & 297 & $85 \mathrm{~kg}$ & $230 \mathrm{~kg}$ & $315 \mathrm{~kg}$ \\
3 & Malung & 20 & 34 & 54 & $43 \mathrm{~kg}$ & $74 \mathrm{~kg}$ & $117 \mathrm{~kg}$ \\
4 & Krot krot & 63 & 98 & 161 & $60 \mathrm{~kg}$ & $105 \mathrm{~kg}$ & $165 \mathrm{~kg}$ \\
\hline
\end{tabular}

Tabel 2 dapat dilihat secara keseluruhan jumlah hasil tangkapan pada siang hari didominasi oleh ikan pary yaitu sebenyak 87 ekor, yang mempunyai jumlah berat $85 \mathrm{~kg}$. Sedangkan jumlah hasil tangkapan terendah pada saat siang hari adalah ikan malung yaitu sebanyak 20 ekor, dengan jumlah berat $43 \mathrm{~kg}$.

Hasil tangkapan keseluruhan berdasarkan berat pada saat malam hari didominasi oleh ikan senangin sebanyak 206 ekor, yang mempunyai jumlah berat $230 \mathrm{~kg}$. Sedangkan jumlah hasil tangkapan terendah secara keseluruhan pada saat malam hari yaitu ikan malung sebanyak 34 ekor dengan jumlah berat $74 \mathrm{~kg}$.

Hasil penelitian menunjukkan bahwa hasil tangkapan berdasarkan jumlah (ekor) selama 12 hari (12 trip) hasil tangkapan terbanyak terjadi pada malam hari sebanyak 407 ekor dan siang hari sebanyak 261 ekor seperti pada Tabel 3

Tabel 3. Perbandingan jumlah ekor ikan pada siang dan malam hari

\begin{tabular}{llllll}
\hline No & Hari/ Bulan & Km. S27 & Km. Tiga Putra 06 & Jumlah & Rata Rata \\
\hline 1 & Siang hari & 107 & 154 & 261 & 63.660 \\
2 & Malam hari & 289 & 118 & 407 & 40.025 \\
\hline & Jumlah & 396 & 272 & 668 & 103.685 \\
\hline
\end{tabular}

Tabel 3 dapat dilihat jumlah hasil tangkapan berdasarkan jumlah individu yang tertangkap selama penelitian adalah sebanyak 668 ekor. Jumlah hasil tangkapan berdasarkan jumlah individu ikan pada malam hari lebih banyak dibandingkan dengan jumlah hasil tangkapan pada siang hari yaitu sebanyak 407 ekor dengan rata-rata hasil tangkapan malam hari 63.660. Sedangkan jumlah hasil tangkapan berdasarkan jumlah individu pada siang hari sebanyak 261 ekor dengan rata-rata hasil tangkapannya adalah 40.025 .

Hasil tangkapan tertinggi pada siang hari pada Km. S27 yaitu sebanyak 107 ekor dan hasil tangkapan siang hari pada $\mathrm{Km}$. Tiga putra 06 yaitu sebanyak 154 ekor. Sedangkan hasil tangkapan berdasarkan individu pada malam hari pada Km. S27 yaitu sebanyak 118 ekor dan hasil tangkapan terendah pada 
malam hari pada $\mathrm{Km}$. Tiga putra 06 adalah sebanyak 289 ekor.

Selama melakukan penelitian di Panipahan Kecamatan Pasir Limau Kapas Kabupaten Rokan Hilir Provinsi Riau jenis ikan yang tertangkap menggunakan alat tangkap Rawai pada saat siang dan malam hari terdiri dari 4 jenis ikan yaitu ikan pari (Dasyatidae), ikan senangin (Eleutheronema tetradactylum), ikan malong (Muraenesox cinereus) dan ikan krot krot (pomadasys hasta), merupakan komoditas air laut yang biasanya hidup berkelompok. Hasil tangkapan yang diperoleh selama penelitian 12 hari (12 trip penangkapan) dengan menggunakan alat tangkap Rawai adalah sebanyak 668 ekor yang memiliki berat $668 \mathrm{~kg}$. Dimana jumlah hasil tangkapan siang hari sebanyak 261 ekor dengan berat $333 \mathrm{~kg}$, sedangkan jumlah hasil tangkapan malam hari sebanyak 407 ekor dengan berat $517 \mathrm{~kg}$.

Adapun hasil tangkapan perjenis ikan alat tangkap Rawai selama penelitian adalah ikan pari 156 ekor dengan berat $253 \mathrm{~kg}$, ikan senangin berjumlah 297 ekor dengan berat $315 \mathrm{~kg}$, ikan malong berjumlah 54 ekor dengan berat $117 \mathrm{~kg}$ dan ikan krot krot berjumlah 161 ekor dengan berat $165 \mathrm{~kg}$.

Jika dilihat dari jumlah berat hasil tangkapan terdapat perbedaan jumlah hasil tangkapan antara siang hari dan malam hari, dimana hasil tangkapan malam hari lebih banyak dibandingkan dengan malam hari, sedangkan jika dilihat dari jumlah individu hasil tangkapan tersebut juga terdapat perbedaan antara siang hari dan malam hari, dimana hasil tangkapan malam hari lebih banyak dibandingkan siang hari, hal itu disebebkan oleh adanya perbedaan ukuran tubuh ikan, dimana ukuran tubuh ikan yang didapat malam hari lebih kecil daripada ukurun tubuh ikan siang hari. Menurut Nursahira et al. (2020), Hasil tangkapan pada malam hari lebih banyak dibandingkan siang hari disebabkan karena tingkah lak ikan pada umumnya yang aktif mencari makan pada malam hari.

\section{Kesimpulan dan Saran}

Hasil tangkapan yang diperoleh selama penelitian 12 hari (12 trip penangkapan) dengan menggunakan alat tangkap Rawai adalah sebanyak 668 ekor dengan berat 850 $\mathrm{kg}$. Rincinya jumlah hasil tangkapan siang hari sebanyak 261 ekor dengan berat $333 \mathrm{~kg}$, sedangkan jumlah hasil tangkapan malam hari sebanyak 407 ekor dengan berat $517 \mathrm{~kg}$.

Hasil tangkapan menurut jumlah berat yang paling banyak siang hari pada KM. S27 yaitu sebanyak $174 \mathrm{~kg}$, sedangkan hasil tangkapan menurut jumlah berat yang paling banyak malam hari pada KM. S27 yaitu sebanyak $320 \mathrm{~kg}$. Hasil tangkapan menurut jumlah ekor yang paling banyak siang hari pada KM. Tiga Putra 06 yaitu sebanyak 154 ekor, sedangkan hasil tangkapan menurut jumlah ekor yang paling banyak saat malam hari pada KM. S27 yaitu sebanyak 289 ekor.

Rata-rata ikan yang mendominasi tertangkap pada siang hari yaitu ikan pari 145 kg (87 ekor), dan pada malam hari ikan yang mendominasi hasil tangkapan yaitu ikan senangin $230 \mathrm{~kg}$ (206 ekor).

Berdasarkan hasil penelitian yang telah dilakukan dapat dilihat hasil tangkapan malam hari lebih banyak dari pada siang hari, oleh sebab itu disarankan nelayan lebih baik melakukan penangkapan pada malam hari, serta menambah waktu lamanya penengelaman alat tangkap agar hasil tangkapannya juga meningkat. Sebaiknya untuk keakuratan data dalam penelitian data didukung oleh data minimal 1 tahun atau 1 musim periode penangkapan.

\section{Daftar Pustaka}

Monitja, D. (2001). Pemanfaatan Sumberdaya Pesisir dalam Bidang Perikanan Tangkap. Prosiding Pelatihan Pengelolaan Wilayah Pesisir Terpadu. Pusat Kajian Sumberdaya Pesisir dan Laut. Institut Pertanian Bogor.

Nursahira., Bustari, dan J. Zain. (2020). Perbandingan Hasil Tangkapan Siang dan Malam pada Alat Tangkap Trammel Net Di Desa Prapat Tunggal Kabupaten Bengkalis Provinsi Riau. Jurnal Online Mahasiswa Fakultas Perikanan dan Kelautan Universitas Riau 2(2): 1-12

Sembiring, M., R. Hendri, dan E. Yulinda. (2020). Kontribusi Sektor Perikanan Tangkap Kecamatan Pasir Limau Kapas terhadap Produk Domestik Regional Bruto (Pdrb) di Kabupaten Rokan Hilir Provinsi Riau. Jurnal Sosial Ekonomi Pesisir, 1(2): 22-29 
Wijayanti, A.C.W., H. Boesono, A.N. Bambang. (2015). Analisis Ekonomi Rawai Dasar dengan $J$ Hook dan Circle Hook Di PPI Ujungbatu Jepara Jawa Tengah. Journal of Fisheries Resources Utilization Management and Technology, 4(4):179-187. 